\title{
Solid Phase Extraction Method for the Determination of Atrazine and Cyanazine in Water Samples
}

\author{
N. A. Z. Abidin ${ }^{1 *}$, Aqilah Abdullah ${ }^{1}$, N.S Abu Kassim ${ }^{1}$ and Noor Hidayah Pungot $^{2}$ \\ ${ }^{1}$ Faculty of Applied Sciences, Universiti Teknologi MARA, Cawangan Negeri Sembilan, Kampus Kuala Pilah, Pekan Parit \\ Tinggi, 72000 Kuala Pilah, Negeri Sembilan, Malaysia \\ ${ }^{2}$ Faculty of Applied Sciences, Universiti Teknologi MARA, 40450 Shah Alam, Selangor, Malaysia
}

\begin{abstract}
Triazine is one of the herbicides group that is widely used in agriculture that acts as an inhibitor for the growth of unwanted weeds in plants. The use of this herbicide on plants is absorbed by the soil and flows into a nearby water system. This research focused on two types of triazines, namely atrazine and cyanazine. This research aims to extract this type of triazine herbicides and to determine their concentration in water samples. It was quantified by using gas chromatographyelectron capture detector (GC-ECD). Solid phase extraction (SPE) method was applied to extract herbicides from water samples. The results indicate that all the samples contained atrazine and cyanazine. Studies in the range of $0.5-25 \mathrm{mg} / \mathrm{L}$ achieved good linearity with good correlation of determination, $\mathrm{r}^{2}$ value of 0.9922 - $0.9982 \mathrm{mg} / \mathrm{L}$. Relative standard deviations (RSD) for triplicate analysis of the samples were less than 10.0\%. The limit of detection (LODs) and limit of quantification (LOQs) of cyanazine and atrazine were found, ranging from $3.33-6.67 \mu \mathrm{g} / \mathrm{L}$ and $11.09-20.10 \mu \mathrm{g} / \mathrm{L}$, respectively. The recoveries of the triazine herbicides studied in water samples ranged from $82.5 \%$ to $107.6 \%$. The developed method exhibited excellent clean-up capability and was successfully applied for determining triazine herbicide residues in water samples.
\end{abstract}

Keywords: triazine herbicides; atrazine; cyanazine; solid phase extraction; gas chromatography

\section{INTRODUCTION}

In the stream of development in technology, especially in the plantation sector may lead to the rises of the environmental pollution. One of the factors is because of the contamination of herbicides. Herbicides are widely used in agriculture to increase the quality of crops (Jose et al., 2013) at the same time have led to major environmental problems when they are discharged to the environment.

This phytotoxic chemical that is mainly used for destroying various weeds and hindering their growth. It can be classified into different groups based on their chemical nature and mechanism of action (Gupta, 2014). Herbicides are mobile and soluble in water and can be absorbed by the soil. According to Solomon et al. (2013), the excess concentration of herbicides in water is toxic to other forms of organisms such as animals and aquatic life. It can also affect human health due to the water that is exposed to the herbicides and consumed as drinking water.

Atrazine and cyanazine are the most commonly used herbicides for weed control in rice fields of Peninsular Malaysia (Jose et. al., 2013; Mohd et. al., 2018; Zhou \& Gao, 2014). Due to the widespread and prolonged use, high chemical stability and water solubility, the residues of triazines herbicides would enter surface water and other environmental water through the ecological chain (Amelin et. al., 2013; Gang et al., 2003). It has been reported that triazines and its degradation products are very toxic, they can disturb and damage endocrine and reproductive systems of 
animals, and cause birth defects, weight loss of embryos and even multiple kinds of cancer (An et al., 2010).

Few analytical instruments have been applied for the analysis of trace triazines in environmental samples. Herrera et al. (2015), have evaluated that gas chromatography (GC) is the most favourable method for separating and analysing the triazine herbicides. It is used to separate and analyse the complex compounds in analytical chemistry without decompose the compound itself. GC is capable of dealing with volatile analytes. Moreover, GC method is extensively used for quantification studies by the reason of thermal stability of these compounds during analysis (Sharma et. al., 2017; Tankiewicz et al., 2010). Various selective detectors are used in trace analysis of herbicides. The electron-capture detector (ECD) was first used for the determination of halogencontaining compounds or halogenated derivatives due to its high sensitivity for these compounds. Therefore, GC-ECD is one of the instruments that can provide accurate analysis in determining the triazine herbicides, and this technique is the most preferable and recommended to determine the halogencontaining organic compounds such as herbicides in water samples (Tandon et al., 2015).

According to Tankiewicz et al. (2010), prior to analysis by GC, the water samples need to undergo separation technique to determine the trace component of triazines in water samples. Determination of triazines in real samples is challenging because of their low concentration and the complexity of real sample matrix (Philisiwe \& Precious, 2019). Sample pre-treatment techniques are usually needed prior to instrumental measurement. The most favourable technique that is widely used is solid phase extraction (SPE). In SPE, cartridges or disk form is used to separate one or more compounds in a liquid mixture by passing the liquid which is known as the mobile phase through a solid that acts as the stationary phase. The separation is due to their different physical or chemical interactions, called hydrophobic interaction where the mobile phase is polar and the stationary phase is non-polar. It is also known as reversed phase of extraction in SPE. SPE has been proven as the best and commonly used technique of extracting target analyte from water samples due to its ability to clean up interferences with low consumption of solvents and time (Oluseyi et al., 2011).
Thus, the aim of this study is to determine the concentrations of atrazine and cyanazine in water samples prior to the analysis by using gas chromatography with electron capture detector (GC-ECD).

\section{MATERIALS AND METHOD}

\section{A. Chemicals and Reagent}

All reagents and solvents used were of analytical grade or HPLC grade. Methanol, ethyl acetate and triazine standard solution of atrazine and cyanazine were purchased from Dr. Ehrenstorfer GmbH (Augsburg, Germany). All compounds had a purity of higher than 97\%. Deionized water was prepared in-house using a Millipore Milli-Q system (USA).

\section{Preparation of standards and sample solutions}

Stock solutions in $1000 \mathrm{mg} / \mathrm{L}$ of atrazine and cyanazine compounds were prepared in methanol and stored in freezer at $4^{\circ} \mathrm{C}$. All working solutions were prepared by serial dilution concentration of stock of $0.5,1,5,15$ and $25 \mathrm{mg} / \mathrm{L}$.

\section{Gas Chromatography - Electron Capture Detector (GC- ECD) procedure}

An Agilent Technologies 7820 A system gas chromatography equipped with an electron capture detector (ECD) and $30 \mathrm{~m}$ x $250 \mu \mathrm{m} \mathrm{HP} 5$-MS capillary column (Agilent Technologies, CA, USA) was used for separations. Nitrogen gas has been set up as make up gas with constant flow of $1.5 \mathrm{~mL} / \mathrm{min}$. The initial temperature was set as $80^{\circ} \mathrm{C}$ and hold for $1 \mathrm{~min}$. Afterwards, the temperature was increased by $20^{\circ} \mathrm{C} / \mathrm{min}$ until it reached $200^{\circ} \mathrm{C}$. The final temperature has been programmed to $250^{\circ} \mathrm{C}$ and hold for $1 \mathrm{~min}$ at a speed of $10^{\circ} \mathrm{C} / \mathrm{min}$. The overall run time was $15 \mathrm{~min}$. The temperature of initial injector that has been used in this study is $225^{\circ} \mathrm{C}$ and the detector temperature was at $280^{\circ} \mathrm{C}$ with a flowrate of 1.5 $\mathrm{mL} / \mathrm{min}$ and $1 \mu \mathrm{L}$ of triazine standards was injected into injection port using spitless mode.

\section{Sampling and pre-treatment of samples}

Water samples were collected from rice field at Jalan Bukit Kepis-Juasseh, Kampung Sawah Lebar, Negeri Sembilan. The water samples were taken from three different sampling points; point A, point $\mathrm{B}$ and point $\mathrm{C}$. Point $\mathrm{A}$ was from the rice 
field area (stagnant water), point B was from water stream a (run-off from nearby area) and point $\mathrm{C}$ was from water stream b (conventional irrigation supply). Water samples (1 L) were taken from the upper $50 \mathrm{~cm}$ surface of the water using polyethylene buckets that had been pre-cleaned and rinsed with water samples. The samples were then transferred to high density polyethylene (HDPE) bottles and labelled as A, $\mathrm{B}$, and C. Water samples were filtered by using $0.45 \mu \mathrm{m}$ pore size membrane to discard any suspended particles from the samples. Samples were kept in refrigerator at temperature of $4^{\circ} \mathrm{C}$ until analysis.

\section{Solid phase extraction (SPE) procedure}

The SPE cartridges were conditioned by using $5 \mathrm{~mL}$ of methanol for 30 seconds to wet and activate the sorbent surface. Then, the cartridges were rinsed with $10 \mathrm{~mL}$ of distilled water without applying vacuum. Filtered water sample $(50$ - $100 \mathrm{~mL}$ ) was added to pre-condition column using a vacuum at flow rate of $40-45 \mathrm{~mL} / \mathrm{min}$. Then, the column was dried for 15 min by using vacuum. Next, the absorbed residue was eluted with $5 \mathrm{~mL}$ of ethyl acetate and evaporated under a gentle stream of nitrogen gas at room temperature to make it concentrated to $1 \mathrm{~mL}$ prior to $\mathrm{GC}$ analysis.

\section{Method validation}

The calibration standards (five levels) were prepared in mobile phase following concentration ranges: $0.5,1,5,15$, and $25 \mathrm{mg} / \mathrm{L}$ for every individual analyte. Linearity was assessed by plotting peak arrangement concentration of the analyte against response peak area using linear regression analysis. Precision and repeatability were determined by analyzing triplicate of each sample for five days interval followed by the calculation of the percentage relative standard deviation for each compound.

Recovery was assessed by analyzing the concentration of each analyte in triplicate aliquots of spiked and unspiked samples. Each aliquot of sample was spiked to give an added concentration similar to the second level of the calibration range used in this study. The on-column limit of detection was estimated as $3 \times$ signal/noise ratio and limit of quantitation as $10 \times$ signal/noise ratio for each compound.

\section{RESULTS AND DISCUSSION}

\section{A. Chromatographic Separation}

Temperature programming of $12 \mathrm{mins}$ with $1.5 \mathrm{~mL} / \mathrm{min}$ optimized gas flow gave maximum number of the theoretical plates $(\mathrm{N}=156)$ and high resolution ( $\mathrm{Rs} \sim 10.2 \mathrm{~min})$ thus permitting the elution of atrazine and cyanazine. Figure 1 shows representative chromatographic profile atrazine and cyanazine elution time at $25.0 \mathrm{mg} / \mathrm{L}$.

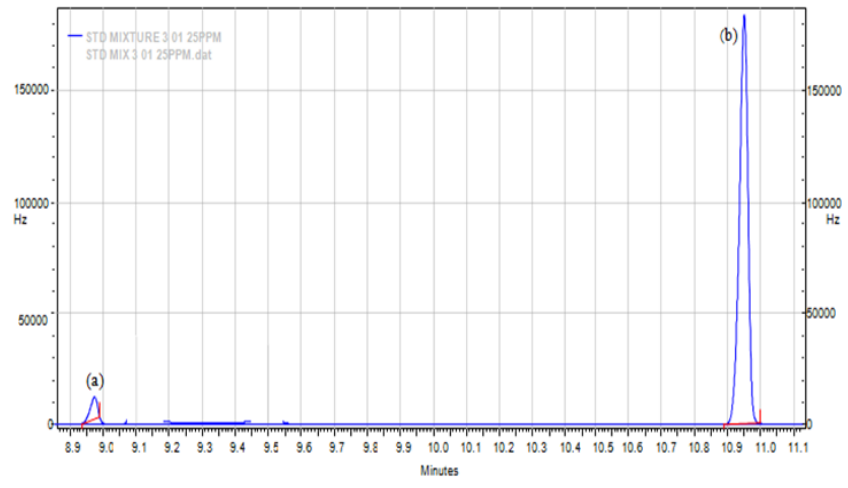

Figure 1. Chromatogram of (a) atrazine and (b) cyanazine at $25.0 \mathrm{mg} / \mathrm{L}$

\section{B. Method Validation}

Table 1 shows the data of correlation coefficients $\left(r^{2}\right)$ of the calibration curves are 0.9922 for atrazine and 0.9982 for cyanazine over the range of $0.5-25.0 \mathrm{mg} / \mathrm{L}$ indicating good linearity. The linear range used throughout does not exceed $25 \mathrm{mg} / \mathrm{L}$ to avoid column degradation and to increase the lifespan of the column. Furthermore, lower concentration will provide more precise result. However, this result is slightly varied with previous study which reported different linearity of atrazine and cyanazine at 0.9991 and 0.9995 , respectively (Sanagi, 2012).

Table 1. The regression equation, correlation coefficients $\left(r^{2}\right)$, and linear range data

\begin{tabular}{clcc}
\hline Triazines & $\begin{array}{c}\text { Regression } \\
\text { equation }\end{array}$ & $\begin{array}{c}\text { Correlation } \\
\text { coefficient } \\
\left(\mathbf{r}^{2}\right)\end{array}$ & $\begin{array}{c}\text { Linear } \\
\text { range } \\
(\mathbf{m g} / \mathbf{L})\end{array}$ \\
\hline Atrazine & $\begin{array}{l}\mathrm{y}=77565 \mathrm{x}+ \\
\text { Cyanazine }\end{array}$ & $\begin{array}{l}0.9922 \\
\mathrm{y}=117926\end{array}$ & $0.5-25.0$ \\
& 139806 & 0.9982 & $0.5-25.0$ \\
\hline
\end{tabular}


The detection limit (LOD) was calculated by comparing the signal-to-noise ratio $(\mathrm{S} / \mathrm{N})$ of the lowest detectable concentration to a $\mathrm{S} / \mathrm{N}=3$. A $\mathrm{S} / \mathrm{N}$ of 10 was applied for the calculation of the quantification limit (LOQ). Based on the result, the LODs was calculated at signal-to-noise ratio of 3 $(\mathrm{S} / \mathrm{N}$ 3) for atrazine and cyanazine were $0.00667 \mathrm{mg} / \mathrm{L}$ and $0.00333 \mathrm{mg} / \mathrm{L}$, respectively. The LOQs were calculated at signal-to-noise ratio of $10(\mathrm{~S} / \mathrm{N} \sim 10)$ for atrazine and cyanazine were $0.0201 \mathrm{mg} / \mathrm{L}$ and $0.01109 \mathrm{mg} / \mathrm{L}$, individually.

These LODs and LOQs that were obtained in our study is higher than the LOD and LOQ that has been stated in Environmental Protection Agency (EPA). EPA reported that LOD are $0.03 \mu \mathrm{g} / \mathrm{L}$ for atrazine and $0.05 \mu \mathrm{g} / \mathrm{L}$ for cyabazine while LOQ recommended by EPA are $3.00 \mu \mathrm{g} / \mathrm{L}$ for atrazine and $2.50 \mu \mathrm{g} / \mathrm{L}$ for cyanazine (Environmental Protection Agency, 2009).

The differences of LODs and LOQs that were obtained in our study would be due to some modification of the methods or should be explore further.

\section{Precision}

Precision and repeatability were determined by analysing triplicate of each sample for five days interval under the same operating conditions and calculated as between-day RSD of peak areas. As can be seen in Table 2, the results obtained were satisfactory with relative standard deviation (RSD) values below $10 \%$ for both compounds.

\section{Extraction Recovery}

To figure out the accuracy of SPE procedure, recovery tests were performed by spiked samples with known concentration. Accordingly, $1.00 \mathrm{mg} / \mathrm{L}$ of standard solution was spiked into $50 \mathrm{~mL}$ sample. The spiked and non-spiked samples were extracted simultaneously by the optimized extraction and concentration of each triazine was determined in triplicate. Table 2 shows the analytical results obtained for the recovery test of triazine herbicides. The acceptable range for most of the triazine herbicides for recovery test were 75 $110 \%$ (Ueji \& Inao, 2014). It shows that the recoveries of atrazine and cyanazine were within the acceptable range with SPE using C18 cartridge. Recovery of the targeted analytes was calculated in Equation (1) as follows:

$$
\text { Percentage recovery }=\frac{C_{S}-C}{S} \times 100
$$

where $\mathrm{Cs}_{\mathrm{s}}$ was stand for concentration of triazines in spike sample, $\mathrm{c}$ was the concentration of triazines in non-spike sample and $\mathrm{s}$ was the known concentration that had been spiked in the sample.

\section{Analysis of Triazine Herbicides in Rice Field Waters}

Rice field water samples were collected and analyzed to support the method development and validation. Surface water samples were taken from three different sampling points namely point A, point B and point C. The collected samples were analyzed by the present method.

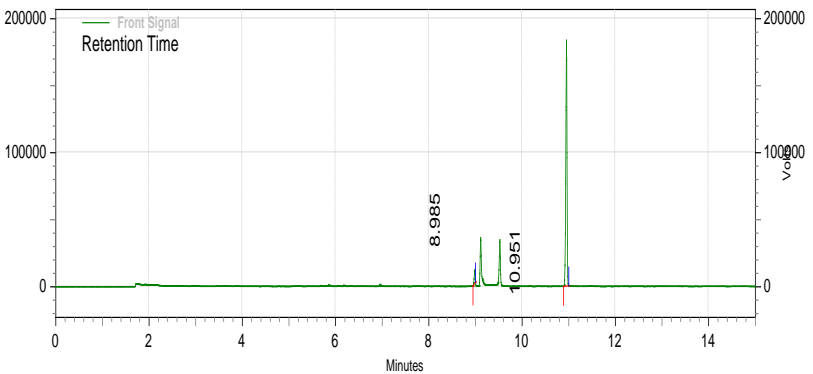

Figure 2. Chromatogram obtained from rice field water sample (sample B) spiked with $1.00 \mathrm{mg} / \mathrm{L}$ mixture of atrazine $\left(t_{R}=8.985\right)$ and cyanazine $\left(t_{R}=10.961\right)$

Atrazine and cyanazine were detected in water samples from all sampling points. The concentration of cyanazine was much higher than atrazine in rice field water samples. The concentration levels of herbicide residues in the rice field water were hardly affected by the herbicide and the volume of standing water at application time when sampling was done (Ismail et al., 2015). The mean level of atrazine and cyanazine for water samples in our study were higher than recommended value by WHO (2010) which is $0.006 \mathrm{mg} / \mathrm{L}$ and $0.001 \mathrm{mg} / \mathrm{L}$, respectively.

Nevertheless, our results provide information of possible contamination by the agrochemical which is triazine herbicides in rice field water at Jalan Bukit Kepis-Juasseh, Kampung Sawah Lebar, Negeri Sembilan and suggest that cleanup and control procedures should be conducted. 
Table 2. Summary of method validation of atrazine and cyanazine

\begin{tabular}{|c|c|c|c|c|c|c|c|}
\hline \multirow{3}{*}{ Triazine } & \multirow{3}{*}{$\begin{array}{l}\text { Type of } \\
\text { sample }\end{array}$} & \multicolumn{2}{|c|}{ Relative Standard } & \multirow{3}{*}{$\begin{array}{c}\text { Recovery } \\
\text { (\%) }\end{array}$} & \multirow{3}{*}{$\begin{array}{c}\text { LOD } \\
(\mathrm{mg} / \mathrm{L})\end{array}$} & \multirow{3}{*}{$\begin{array}{c}\text { LOQ } \\
(\mathrm{mg} / \mathrm{L})\end{array}$} & \multirow{3}{*}{$\begin{array}{c}\text { Concentration } \\
\text { in water sample } \\
(\mathbf{m g} / \mathbf{L}) \pm \mathrm{SD}\end{array}$} \\
\hline & & Devi & n (\%) & & & & \\
\hline & & $\begin{array}{c}\text { Day } 5 \\
(\mathrm{mg} / \mathrm{L})\end{array}$ & $\begin{array}{l}\text { Day } 10 \\
(\mathrm{mg} / \mathrm{L})\end{array}$ & & & & \\
\hline \multirow{3}{*}{ Atrazine } & $\mathrm{A}$ & 0.059 & 0.033 & 82.5 & \multirow{4}{*}{0.00667} & \multirow{4}{*}{0.0201} & $0.520 \pm 0.013$ \\
\hline & B & 0.042 & 0.015 & $85 \cdot 9$ & & & $0.383 \pm 0.006$ \\
\hline & $\mathrm{C}$ & 0.051 & 0.025 & 83.7 & & & $0.213 \pm 0.004$ \\
\hline \multirow{3}{*}{ Cyanazine } & $\mathrm{A}$ & 0.273 & 0.159 & 98.7 & & & $0.760 \pm 0.014$ \\
\hline & B & 0.083 & 0.042 & 107.6 & \multirow{2}{*}{0.00333} & \multirow{2}{*}{0.01109} & $0.806 \pm 0.017$ \\
\hline & $\mathrm{C}$ & 0.154 & 0.079 & 88.6 & & & $0.244 \pm 0.005$ \\
\hline
\end{tabular}

\section{CONCLUSION}

In summary, the level of triazines reported could be related to abundant used on crops that may carry a potential health issue for humans, animals and aquatic life. Although it has been successfully determined for two triazine herbicides using Gas Chromatography Electron Capture Detector (GC ECD), it is suggested to improve the sample preparation by using Magnetic Solid-Phase Extraction (MSPE) method. This method offers lower sensitivity with the exploration of different solvent such as elution. A method will be established with more rapid efficiency and reduce the number of organic reagents used during analysis.

\section{ACKNOWLEDGEMENT}

The authors would like to acknowledge Faculty of Applied Sciences, Universiti Teknologi Mara (UiTM), Negeri Sembilan Branch, Kuala Pilah Campus and Universiti Teknologi MARA, Shah Alam, Selangor for providing the facilities and financial support on this research.

\section{REFERENCES}

Amelin, VG, Bol'shakov, DS \& Tret'yakov, AV 2013, 'Dispersive liquid-liquid microextraction and solid-phase extraction of polar pesticides from natural water and their determination by micellar electrokinetic chromatography', Journal of Analytical Chemistry, no. 68, pp. 386-397.

An, YR, Kim, SJ, Park, HW, Oh, MJ, Kim, YJ, Ryu, JC, \& Hwang, SY 2010, 'Genomic comparison of insecticides and herbicide in human hepatoma (HepG2) cell line', Molecular \& Cellular Toxicology, vol. 6, pp. 378-383.

Cincinnati, $\mathrm{OH}$ 2009, 'Determination of chlorinated pesticides, herbicides, and organohalides by liquid-solid extraction and electron capture gas chromatography', in methods for the determination of organic compounds in drinking water (EPA Report No. EPA-600/4-88/039), Environmental Protection Agency (2009), Method 508.1. Environmental Monitoring Systems Laboratory.

Gang, S \& Lee, HK 2003, 'Determination of triazines in soil by microwave-assisted extraction followed by solid-phase microextraction and gas chromatography-mass spectrometry', Journal of Chromatography A, no. 985, pp. 167-174.

Gupta, PK 2014, 'Herbicides and fungicides', Biomarkers in Toxicology, Elsevier, pp. 389-407.

Herrera, AV, Asensio-Ramos, M, Hernández-Borges, J \& Rodríguez- Delgado, MA 2015, 'Pesticides and herbicides: types, uses, and determination of herbicides', Encyclopedia of Food and Health, pp. 326-332.

Ismail, BS, Prayitno, S \& Tayeb, MA 2015, 'Contamination of rice field water with sulfonylurea and phenoxy herbicides in the Muda Irrigation Scheme, Kedah, Malaysia', Environmental Monitoring and Assessment, vol.7, pp. 187189.

Jose, A, Aguilar-Arteaga, K, Dez, C \& Barrado, E 2013, 'Recent advances in the extraction of triazines from water samples', Herbicides - Advances in Research, pp. 376-305

Mohd, NI, Gopal, K, Raoov, M, Mohamad, S, Yahaya, N, Lim, V \& Zain, NNM 2019, 'Evaluation of a magnetic activated charcoal modified with non-ionic silicone surfactant as a 
new magnetic solid phase extraction sorbent with triazine herbicides as model compounds in selected milk and rice samples', Talanta, no. 196, pp. 217-225.

Oluseyi, T, Olayinka, K, Alo, B \& Smith, RM 2011, 'Improved analytical extraction and clean-up techniques for the determination of PAHs in contaminated soil samples', International Journal of Environmental Research, vol.5, no. 3, pp. 681-69o.

Philisiwe, NK \& Precious NM 2019, 'Development and application of SPE-LC-PDA method for the determination of triazines in water and liquid sludge samples', Journal of Environment Management, no. 249, pp. 1-8.

Rodríguez-González, N, Beceiro-González, E, GonzálezCastro, MJ \& Muniategui-Lorenzo, S 2013, 'Application of a developed method for the extraction of triazines in surface waters and storage prior to analysis to seawaters of Galicia (Northwest Spain)', The Scientific World Journal, pp. 231245 .

Sanagi, MM, Abbas, HH, Ibrahim, WAW \& Aboul-Enien, HY 2012, 'Dispersive liquid-liquid microextraction method based on solidification of floating organic droplet for the determination of triazine herbicides in water and sugarcane samples', Food Chemistry, no. 133, vol. 2, pp. 557-562.

Sharma, DK, Kumar, A \& Mahender 2017, 'A simple and fast solid-phase extraction GC-ECD method for the routine assessment of atrazine residues in agricultural produces', Journal of Chromatography \& Separation Techniques, vol. 8, no. 1, pp. 8-11.

Solomon, KR, Dalhoff, K, Volz, D \& Van Der Kraak, G 2013, 'Effects of herbicides on fish', Fish Physiology, vol. 33, pp. 369-409.

Tandon, S, Kumar, S \& Sand, NK 2015, 'Development and validation of GC-ECD method for the determination of Metamitron in soil', International Journal of Analytical Chemistry, pp. 1-5.

Tankiewicz, M, Fenik, J \& Biziuk, M 2010, 'Determination of organophosphorus and organonitrogen pesticides in water samples', TrAC - Trends in Analytical Chemistry, vol. 29, no. 9, pp. 1050-1063.

Ueji, M \& Inao, K 2014, 'Rice paddy field herbicides and their effects on the environment and ecosystems', Weed Biology and Management, vol. 1, no. 1, pp. 71-79.

World Health Organization, 2010, The WHO recommended classification of pesticides by hazard and guidelines to classification.

Yang, Q, Chen, B, He, M \& Hu, B 2018, 'Sensitive determination of seven triazine herbicide in honey, tomato, and environmental water samples by hollow fiber based liquid-liquid-liquid microextraction combined with sweeping micellar electrokinetic capillary chromatography', Talanta, no. 186, pp. 88-96.

Zhou, Q \& Gao, Y 2014, 'Combination of ionic liquid dispersive liquid-phase microextraction and high performance liquid chromatography for the determination of triazine herbicides in water samples', Chinese Chemical Letters, pp. 8-11. 